\title{
Some new fixed point theorems in metric spaces
}

\author{
Tran VAn An ANd Le Thanh Quan
}

\begin{abstract}
In this paper, the main results of [13] are generalized. Also, examples are given to illustrate the obtained results.
\end{abstract}

\section{INTRODUCTION AND PRELIMINARIES}

In the last fifty years, the contraction condition of Banach contraction principle was generalized to many forms, see $[2,4,10]$ for example. Also, the metric space in Banach contraction principle was generalized to many settings of generalized metric spaces. One of the most interesting ones is the notion of a partial metric space introduced by Matthews [9]. Later, many authors studied various types of fixed point theorems in partial metric spaces, see [1] and references therein. But some authors showed that many fixed point generalizations to partial metric spaces can be obtained from the corresponding results in metric spaces, see more details in $[5,6,12]$.

In [13], Samet et al. established new fixed point theorems on metric spaces and then deduced analogous results on partial metric spaces. Then, many fixed point theorems, including Banach contraction principle, Kannan fixed point theorem, Reich fixed point theorem, Chatterjea fixed point theorem in metric spaces and partial metric spaces were derived.

In this paper, we state some generalizations of the main results in [13]. We also give examples to illustrate the results.

The following notions and results are useful in what follows.

Definition 1.1. [8, Definition 3.1] Let $X$ be a non-empty set and $p: X \times$ $X \longrightarrow[0,+\infty)$ be a function such that for all $x, y, z \in X$,

(1) The small self-distance: $0 \leq p(x, x) \leq p(x, y)$.

(2) The indistancy implies equality: If $p(x, x)=p(x, y)=p(y, y)$ then $x=y$.

(3) The symmetry: $p(x, y)=p(y, x)$.

(4) The triangularity: $p(x, z) \leq p(x, y)+p(y, z)-p(y, y)$.

2000 Mathematics Subject Classification. Primary: 47H10, 54H25; Secondary: 54D99, $54 \mathrm{E} 99$.

Key words and phrases. fixed point; metric; partial metric. 
Then $p$ is called a partial metric and the pair $(X, p)$ is called a partial metric space.

Remark 1.1. [7, Remark 1.5] Let $(X, p)$ be a partial metric space. Then $p(x, y)=0$ implies $x=y$. The reverse implication does not hold. A simple example of a partial metric space with non-zero self-distances is the set $X=[0,+\infty)$ with $p(x, y)=\max \{x, y\}$ for $x, y \in X$.

Definition 1.2. [3, Definitions 4-6] Let $(X, p)$ be a partial metric space.

(1) A sequence $\left\{x_{n}\right\}$ is called convergent to $x \in X$, written as $\lim _{n \rightarrow \infty} x_{n}=$ $x$, if $\lim _{n \rightarrow \infty} p\left(x_{n}, x\right)=p(x, x)$.

(2) A sequence $\left\{x_{n}\right\}$ is called Cauchy if $\lim _{n, m \rightarrow \infty} p\left(x_{n}, x_{m}\right)$ exists and is finite.

(3) $(X, p)$ is called complete if each Cauchy sequence $\left\{x_{n}\right\}$ in $X$ is convergent to some $x \in X$ and $\lim _{m, n \rightarrow \infty} p\left(x_{n}, x_{m}\right)=p(x, x)$.

(4) [11, Definition 2.1] A sequence $\left\{x_{n}\right\}$ is called 0-Cauchy if

$$
\lim _{n, m \rightarrow \infty} p\left(x_{n}, x_{m}\right)=0 .
$$

The space $(X, p)$ is 0 -complete if each 0 -Cauchy sequence $\left\{x_{n}\right\}$ converges to some $x \in X$ such that $p(x, x)=0$.

Lemma 1.1 ( [7]). Let $(X, p)$ be a partial metric space. Then the functions $d_{p}, d_{m}: X \times X \longrightarrow[0,+\infty)$ given by

$$
\begin{aligned}
d_{p}(x, y) & =2 p(x, y)-p(x, x)-p(y, y), \\
d_{m}(x, y) & =\max \{p(x, y)-p(x, x), p(x, y)-p(y, y)\}
\end{aligned}
$$

for all $x, y \in X$, are metrics on $X$.

Lemma 1.2 ([7], Lemma 1.4). (1) A sequence $\left\{x_{n}\right\}$ is Cauchy in a partial metric space $(X, p)$ if and only if $\left\{x_{n}\right\}$ is Cauchy in the metric space $\left(X, d_{p}\right)$.

(2) A partial metric space $(X, p)$ is complete if and only if the metric space $\left(X, d_{p}\right)$ is complete. Moreover

$$
\lim _{n \rightarrow \infty} d_{p}\left(x_{n}, x\right)=0 \Longleftrightarrow p(x, x)=\lim _{n \rightarrow \infty} p\left(x_{n}, x\right)=\lim _{n, m \rightarrow \infty} p\left(x_{n}, x_{m}\right) .
$$

\section{MAIN RESUlTS}

The main result of the paper is as follows.

Theorem 2.1. Let $(X, d)$ be a complete metric spaces, $\varphi: X \longrightarrow[0, \infty)$ be a lower semi-continuous function and $T: X \longrightarrow X$ be a map. Suppose that for any $0<a<b<\infty$, there exists $\gamma(a, b) \in(0,1)$ such that for all $x, y \in X$,

$$
a \leq d(x, y)+\varphi(x)+\varphi(y) \leq b
$$




$$
\Rightarrow d(T x, T y)+\varphi(T x)+\varphi(T y) \leq \gamma(a, b) M(x, y, T, \varphi)
$$

where

$$
M(x, y, T, \varphi)=\max \{d(x, y)+\varphi(x)+\varphi(y), d(x, T x)+\varphi(x)+\varphi(T x)\} .
$$

Then $T$ has a unique fixed point $x^{*} \in X$. Moreover, $\varphi\left(x^{*}\right)=0$.

Proof. Let $x_{0}$ be an arbitrary point in $X$. Consider the sequence $\left\{x_{n}\right\} \subset X$ defined by $x_{n+1}=T x_{n}$ for all $n \geq 0$. If there exists some $n_{0}$ such that $d\left(x_{n_{0}-1}, x_{n_{0}}\right)+\varphi\left(x_{n_{0}-1}\right)+\varphi\left(x_{n_{0}}\right)=0$, then $x_{n_{0}-1}$ will be a fixed point of $T$. So, we can suppose that, for all $n \geq 1$,

$$
0<d\left(x_{n-1}, x_{n}\right)+\varphi\left(x_{n-1}\right)+\varphi\left(x_{n}\right) .
$$

First, we prove that

$$
\lim _{n \rightarrow \infty}\left[d\left(x_{n-1}, x_{n}\right)+\varphi\left(x_{n-1}\right)+\varphi\left(x_{n}\right)\right]=0 .
$$

Indeed, if for some $n_{0} \geq 1$, we have

(4) $d\left(x_{n_{0}-1}, x_{n_{0}}\right)+\varphi\left(x_{n_{0}-1}\right)+\varphi\left(x_{n_{0}}\right)<d\left(x_{n_{0}}, x_{n_{0}+1}\right)+\varphi\left(x_{n_{0}}\right)+\varphi\left(x_{n_{0}+1}\right)$.

Put

$$
a=d\left(x_{n_{0}-1}, x_{n_{0}}\right)+\varphi\left(x_{n_{0}-1}\right)+\varphi\left(x_{n_{0}}\right)
$$

and

$$
b=d\left(x_{n_{0}}, x_{n_{0}+1}\right)+\varphi\left(x_{n_{0}}\right)+\varphi\left(x_{n_{0}+1}\right) .
$$

From (2) and (4), we have

$$
\begin{aligned}
0<a & =d\left(x_{n_{0}-1}, x_{n_{0}}\right)+\varphi\left(x_{n_{0}-1}\right)+\varphi\left(x_{n_{0}}\right) \\
& <d\left(x_{n_{0}}, x_{n_{0}+1}\right)+\varphi\left(x_{n_{0}}\right)+\varphi\left(x_{n_{0}+1}\right)=b .
\end{aligned}
$$

From (1), there exists $\gamma(a, b) \in(0,1)$ such that

$$
\begin{aligned}
& d\left(x_{n_{0}}, x_{n_{0}+1}\right)+\varphi\left(x_{n_{0}}\right)+\varphi\left(x_{n_{0}+1}\right) \\
\leq & \gamma(a, b) \max \left\{d\left(x_{n_{0}-1}, x_{n_{0}}\right)+\varphi\left(x_{n_{0}-1}\right)+\varphi\left(x_{n_{0}}\right),\right. \\
& \left.d\left(x_{n_{0}-1}, x_{n_{0}}\right)+\varphi\left(x_{n_{0}-1}\right)+\varphi\left(x_{n_{0}}\right)\right\} \\
= & \gamma(a, b)\left[d\left(x_{n_{0}-1}, x_{n_{0}}\right)+\varphi\left(x_{n_{0}-1}\right)+\varphi\left(x_{n_{0}}\right)\right] \\
< & d\left(x_{n_{0}-1}, x_{n_{0}}\right)+\varphi\left(x_{n_{0}-1}\right)+\varphi\left(x_{n_{0}}\right)
\end{aligned}
$$

which is a contradiction to (4). So, for each $n \in \mathbb{N}$, if we put

$$
\delta_{n}=d\left(x_{n}, x_{n+1}\right)+\varphi\left(x_{n}\right)+\varphi\left(x_{n+1}\right)
$$

then $\left\{\delta_{n}\right\}$ is a non-increasing sequence of positive real numbers. Hence, there is $r \geq 0$ such that

$$
\lim _{n \rightarrow \infty} \delta_{n}=\lim _{n \rightarrow \infty}\left[d\left(x_{n-1}, x_{n}\right)+\varphi\left(x_{n-1}\right)+\varphi\left(x_{n}\right)\right]=r .
$$

Suppose to the contrary that $r>0$. Then, for all $n \geq 1$, we have

$$
0<r \leq d\left(x_{n-1}, x_{n}\right)+\varphi\left(x_{n-1}\right)+\varphi\left(x_{n}\right) \leq \delta_{0} .
$$


From (1), there exists $\gamma\left(r, \delta_{0}\right) \in(0,1)$ such that

$$
\begin{aligned}
& d\left(x_{n}, x_{n+1}\right)+\varphi\left(x_{n}\right)+\varphi\left(x_{n+1}\right) \\
\leq & \gamma\left(r, \delta_{0}\right) \max \left\{d\left(x_{n-1}, x_{n}\right)+\varphi\left(x_{n-1}\right)+\varphi\left(x_{n}\right),\right. \\
& \left.d\left(x_{n-1}, x_{n}\right)+\varphi\left(x_{n-1}\right)+\varphi\left(x_{n}\right)\right\} \\
= & \gamma\left(r, \delta_{0}\right)\left[d\left(x_{n-1}, x_{n}\right)+\varphi\left(x_{n-1}\right)+\varphi\left(x_{n}\right)\right] .
\end{aligned}
$$

Taking the limit as $n \rightarrow \infty$ in (8) and using (6), we get $r \leq \gamma\left(r, \delta_{0}\right) r$ which implies that $\gamma\left(r, \delta_{0}\right) \geq 1$. It is a contradiction. Thus $r=0$ and (3) holds.

Next, we prove that $\left\{x_{n}\right\}$ is a Cauchy sequence in $(X, d)$. Suppose to the contrary that $\left\{x_{n}\right\}$ is not a Cauchy sequence in $(X, d)$. Then there exists $\varepsilon>0$ for which we can find two sequences of positive integers $\{m(k)\}$ and $\{n(k)\}$ such that for all positive integers $k$,

$$
n(k)>m(k)>k, d\left(x_{m(k)}, x_{n(k)}\right) \geq \varepsilon, d\left(x_{m(k)}, x_{n(k)-1}\right)<\varepsilon .
$$

From (9), we have

$$
\begin{aligned}
\varepsilon & \leq d\left(x_{m(k)}, x_{n(k)}\right) \\
& \leq d\left(x_{m(k)}, x_{n(k)-1}\right)+d\left(x_{n(k)-1}, x_{n(k)}\right) \\
& <\varepsilon+d\left(x_{n(k)}, x_{n(k)-1}\right) .
\end{aligned}
$$

Taking the limit as $k \rightarrow \infty$ in (10) and using (3), we obtain

$$
\lim _{k \rightarrow \infty} d\left(x_{m(k)}, x_{n(k)}\right)=\varepsilon .
$$

On the other hand, we have

$$
\begin{aligned}
d\left(x_{n(k)}, x_{m(k)}\right) \leq & d\left(x_{n(k)}, x_{n(k)+1}\right)+d\left(x_{n(k)+1}, x_{m(k)+1}\right) \\
& +d\left(x_{m(k)+1}, x_{m(k)}\right)
\end{aligned}
$$

and

$$
\begin{aligned}
d\left(x_{n(k)+1}, x_{m(k)+1}\right) \leq & d\left(x_{n(k)+1}, x_{n(k)}\right)+d\left(x_{n(k)}, x_{m(k)}\right) \\
& +d\left(x_{m(k)}, x_{m(k)+1}\right) .
\end{aligned}
$$

From (12) and (13), we get

$$
\begin{aligned}
& \left|d\left(x_{n(k)+1}, x_{m(k)+1}\right)-d\left(x_{n(k)}, x_{m(k)}\right)\right| \\
\leq & d\left(x_{n(k)+1}, x_{n(k)}\right)+d\left(x_{m(k)+1}, x_{m(k)}\right) .
\end{aligned}
$$

Taking the limit as $k \rightarrow \infty$ in (14), and using (3) and (11), we obtain

$$
\lim _{k \rightarrow \infty} d\left(x_{m(k)+1}, x_{n(k)+1}\right)=\varepsilon .
$$

From (3), we see that there exists $M=\sup _{n \in \mathbb{N}} 2 \varphi\left(x_{n}\right)$. From (9) and (7), for all $k \in \mathbb{N}$, we have

$$
\begin{aligned}
\varepsilon & \leq d\left(x_{m(k)}, x_{n(k)}\right)+\varphi\left(x_{m(k)}\right)+\varphi\left(x_{n(k)}\right) \\
& \leq d\left(x_{m(k)}, x_{n(k)-1}\right)+d\left(x_{n(k)-1}, x_{n(k)}\right)+M \\
& \leq \varepsilon+\delta_{0}+M .
\end{aligned}
$$


Using (16) and (1), there exists $\gamma\left(\varepsilon, \varepsilon+\delta_{0}+M\right) \in(0,1)$ such that

$$
\begin{aligned}
& d\left(x_{n(k)+1}, x_{m(k)+1}\right)+\varphi\left(x_{n(k)+1}\right)+\varphi\left(x_{m(k)+1}\right) \\
\leq & \gamma\left(\varepsilon, \varepsilon+\delta_{0}+M\right) \max \left\{d\left(x_{m(k)}, x_{n(k)}\right)+\varphi\left(x_{m(k)}\right)+\varphi\left(x_{n(k)}\right),\right. \\
& \left.d\left(x_{n(k)}, x_{n(k)+1}\right)+\varphi\left(x_{n(k)}\right)+\varphi\left(x_{n(k)+1}\right)\right\} .
\end{aligned}
$$

Taking the limit as $k \rightarrow \infty$ in (17) and using (3), (11), (15), we obtain

$$
\varepsilon \leq \gamma\left(\varepsilon, \varepsilon+\delta_{0}+M\right) \varepsilon .
$$

Therefore, $\gamma\left(\varepsilon, \varepsilon+\delta_{0}+M\right) \geq 1$. It is a contradiction to the fact that $\gamma\left(\varepsilon, \varepsilon+\delta_{0}+M\right) \in(0,1)$. Hence, we deduce that $\left\{x_{n}\right\}$ is a Cauchy sequence in $(X, d)$. Since $(X, d)$ is complete, there exists $x^{*} \in X$ such that

$$
\lim _{n \rightarrow \infty} x_{n}=x^{*} .
$$

Next, we prove that

$$
\varphi\left(x^{*}\right)=0 .
$$

From (3), we have

$$
\lim _{n \rightarrow \infty} \varphi\left(x_{n}\right)=0 .
$$

Since $\varphi$ is lower semi-continuous, it follows that

$$
0 \leq \varphi\left(x^{*}\right) \leq \liminf _{n \rightarrow \infty} \varphi\left(x_{n}\right)=\lim _{n \rightarrow \infty} \varphi\left(x_{n}\right)=0 .
$$

Then (19) holds.

Now, we prove that $x^{*}$ is a fixed point of $T$. Denote

$$
I=\left\{n \in \mathbb{N}: x_{n}=x^{*}\right\} \text { and } J=\left\{n \in \mathbb{N}: x_{n} \neq x^{*}\right\} .
$$

Since $I \cup J=\mathbb{N}$, at least one of $I$ and $J$ is infinite.

Case 1. I is infinite. We can find a subsequence $\left\{x_{n(p)}\right\}$ of $\left\{x_{n}\right\}$ such that $x_{n(p)}=x^{*}$ for all $p \in \mathbb{N}$. Since $x_{n(p)+1}=T x_{n(p)}=T x^{*}$ and $\lim _{p \rightarrow \infty} x_{n(p)+1}=$ $x^{*}$, we have $x^{*}=T x^{*}$. That is, $x^{*}$ is a fixed point of $T$.

Case 2. $J$ is infinite. We can find a subsequence $\left\{x_{n(p)}\right\}$ of $\left\{x_{n}\right\}$ such that $d\left(x_{n(p)}, x^{*}\right)>0$ for all $p \in \mathbb{N}$. Then, for each $p$, we can find $0<A_{p}<B_{p}$ such that

$$
A_{p} \leq d\left(x_{n(p)}, x^{*}\right)+\varphi\left(x_{n(p)}\right)+\varphi\left(x^{*}\right) \leq B_{p} .
$$

From (1), there exists $\gamma\left(A_{p}, B_{p}\right) \in(0,1)$ such that

$$
\begin{aligned}
& d\left(x_{n(p)+1}, T x^{*}\right)+\varphi\left(x_{n(p)+1}\right)+\varphi\left(T x^{*}\right) \\
\leq & \gamma\left(A_{p}, B_{p}\right) \max \left\{d\left(x_{n(p)}, x^{*}\right)+\varphi\left(x_{n(p)}\right)+\varphi\left(x^{*}\right),\right. \\
& \left.d\left(x_{n(p)}, x_{n(p)+1}\right)+\varphi\left(x_{n(p)}\right)+\varphi\left(x_{n(p)+1}\right)\right\} .
\end{aligned}
$$

Note that, by (18), (19) and (20), we have

$$
\lim _{p \rightarrow \infty}\left[d\left(x_{n(p)}, x^{*}\right)+\varphi\left(x_{n(p)}\right)+\varphi\left(x^{*}\right)\right]
$$




$$
=\lim _{p \rightarrow \infty}\left[d\left(x_{n(p)}, x_{n(p)+1}\right)+\varphi\left(x_{n(p)}\right)+\varphi\left(x_{n(p)+1}\right)\right]=0 .
$$

Then taking the limit as $p \rightarrow \infty$ in (21) and using (18) and (20), we have

$$
d\left(x^{*}, T x^{*}\right)+\varphi\left(T x^{*}\right) \leq 0 .
$$

So $d\left(x^{*}, T x^{*}\right)=0$, that is $x^{*}=T x^{*}$. Therefore, $x^{*}$ is a fixed point of $T$.

Finally, we prove that the fixed point of $T$ is unique. Suppose that $y^{*} \in X$ is another fixed point of $T$, that is, $T y^{*}=y^{*}$ and $d\left(x^{*}, y^{*}\right)>0$. Since $d\left(x^{*}, y^{*}\right)>0$, we can find $0<\alpha<\beta$ such that

$$
\alpha \leq d\left(x^{*}, y^{*}\right)+\varphi\left(x^{*}\right)+\varphi\left(y^{*}\right) \leq \beta .
$$

From (1), we have

$$
\begin{aligned}
& d\left(x^{*}, y^{*}\right)+\varphi\left(x^{*}\right)+\varphi\left(y^{*}\right) \\
\leq & d\left(T x^{*}, T y^{*}\right)+\varphi\left(T x^{*}\right)+\varphi\left(T y^{*}\right) \\
\leq & \gamma(\alpha, \beta) \max \left\{d\left(x^{*}, y^{*}\right)+\varphi\left(x^{*}\right)+\varphi\left(y^{*}\right), d\left(x^{*}, T x^{*}\right)+\varphi\left(x^{*}\right)+\varphi\left(T x^{*}\right)\right\} \\
= & \gamma(\alpha, \beta) \max \left\{d\left(x^{*}, y^{*}\right)+\varphi\left(x^{*}\right)+\varphi\left(y^{*}\right), d\left(x^{*}, x^{*}\right)+\varphi\left(x^{*}\right)+\varphi\left(x^{*}\right)\right\} \\
= & \gamma(\alpha, \beta)\left[d\left(x^{*}, y^{*}\right)+\varphi\left(x^{*}\right)+\varphi\left(y^{*}\right)\right] .
\end{aligned}
$$

Then $\gamma(\alpha, \beta) \geq 1$. It is a contradiction to $\gamma(\alpha, \beta) \in(0,1)$. This proves that the fixed point of $T$ is unique.

Remark 2.1. In 2010, Tasković proved general results for the existence, not for the uniqueness, of the fixed point of a map $T: X \longrightarrow X$ on some topological space $X[14$, Theorem 3, Corollary 1]. Tasković's results are very general but Theorem 2.1 may not be derived directly from them. For example, put $M(x)=M(x, T x, T, \varphi)$, that is,

$$
M(x)=d(x, T x)+\varphi(x)+\varphi(T x) .
$$

From (1), if $a \leq M(x) \leq b$, then $M(T x) \leq \gamma(a, b) M(x) \leq M(x)$. So, the condition (M') in [14, Corollary 1] is satisfied for $x$ satisfying $M(x) \in[a, b]$, not for all $x \in X$.

Moreover, if $M(x) \in[a, b]$ for all $x \in X$, then the condition (M') in [14, Corollary 1] is satisfied. However, we get

$$
0<a \leq \lim _{n \rightarrow \infty} \sup _{i \geq n} M\left(T^{i} x\right), \lim _{n \rightarrow \infty} \sup _{i \geq 2 n} M\left(T^{i} x\right), \lim _{n \rightarrow \infty} \sup _{i \geq 2 n+1} M\left(T^{i} x\right) \leq b
$$

if the limits exist. So, $M(t) \leq \lim _{n \rightarrow \infty} \sup _{i \geq n} M\left(T^{i} x\right)$ or $M(t) \leq \lim _{n \rightarrow \infty} \sup _{i \geq 2 n} M\left(T^{i} x\right)$ or $M(t) \leq \lim _{n \rightarrow \infty} \sup _{i \geq 2 n+1} M\left(T^{i} x\right)$ may not imply $T(t)=t$. Then $X$ may not satisfy the so-called condition of local sup TCS-convergence [14, page 21].

From Theorem 2.1, we get [13, Theorem 2.1] as a direct consequence.

Corollary 2.1 ([13], Theorem 2.1). Let $(X, d)$ be a complete metric spaces, $\varphi: X \rightarrow[0, \infty)$ be a lower semi-continuous function and $T: X \rightarrow X$ be a 
map. Suppose that for any $0<a<b<\infty$, there exists $0<\gamma(a, b)<1$ such that for all $x, y \in X$,

$$
\begin{aligned}
& a \leq d(x, y)+\varphi(x)+\varphi(y) \leq b \\
\Rightarrow \quad & d(T x, T y)+\varphi(T x)+\varphi(T y) \leq \gamma(a, b)[d(x, y)+\varphi(x)+\varphi(y)] .
\end{aligned}
$$

Then $T$ has a unique fixed point $z \in X$. Moreover, $\varphi(z)=0$.

The following example shows that Theorem 2.1 is a proper generalization of Corollary 2.1 for a map $T$ on a complete metric space $(X, d)$ with some $\varphi$.

Example 2.1. Let $X=[0,1]$ with the usual metric $d, \varphi(x)=0$ for all $x \in X$ and

$$
T x= \begin{cases}\frac{1}{2}, & \text { if } x \in[0,1) ; \\ \frac{3}{8}, & \text { if } x=1 .\end{cases}
$$

Then $(X, d)$ is a complete metric space and $\varphi$ is lower semi-continuous. We see that

$$
\begin{gathered}
d\left(T \frac{7}{8}, T 1\right)+\varphi\left(T \frac{7}{8}\right)+\varphi(T 1)=\left|\frac{1}{2}-\frac{3}{8}\right|+0+0=\frac{1}{8} \\
d\left(\frac{7}{8}, 1\right)+\varphi\left(\frac{7}{8}\right)+\varphi(1)=\left|\frac{7}{8}-1\right|+0+0=\frac{1}{8} .
\end{gathered}
$$

Then Corollary 2.1 is not applicable to $T$ and $\varphi$ on $(X, d)$. However, if $x, y \in[0,1)$, then (1) obviously holds. If $x \in[0,1)$ and $y=1$, we have

$$
\begin{aligned}
d(T x, T y)+ & \varphi(T x)+\varphi(T y)=d(T x, T 1)+\varphi(T x)+\varphi(T 1)=\left|\frac{1}{2}-\frac{3}{8}\right|=\frac{1}{8}, \\
& \max \{d(x, y)+\varphi(x)+\varphi(y), d(x, T x)+\varphi(x)+\varphi(T x)\} \\
= & \max \{d(x, 1)+\varphi(x)+\varphi(1), d(x, T x)+\varphi(x)+\varphi(T x)\} \\
= & \max \left\{|x-1|,\left|x-\frac{1}{2}\right|\right\} \\
\geq & \frac{1}{4} .
\end{aligned}
$$

If $y \in[0,1)$ and $x=1$, we have

$$
d(T x, T y)+\varphi(T x)+\varphi(T y)=d(T 1, T y)+\varphi(T 1)+\varphi(T y)=\left|\frac{1}{2}-\frac{3}{8}\right|=\frac{1}{8}
$$

and

$$
\begin{aligned}
& \max \{d(x, y)+\varphi(x)+\varphi(y), d(x, T x)+\varphi(x)+\varphi(T x)\} \\
= & \max \{d(1, y)+\varphi(1)+\varphi(y), d(1, T 1)+\varphi(1)+\varphi(T 1)\} \\
= & \max \left\{|1-y|,\left|1-\frac{3}{8}\right|\right\} \\
\geq & \frac{5}{8} .
\end{aligned}
$$


By the above, we see that (1) holds with $\gamma(a, b)=\frac{1}{2}$. Then Theorem 2.1 is applicable to $T$ and $\varphi$ on $(X, d)$.

The following example shows that we can not add both

$$
d(x, T y)+\varphi(x)+\varphi(T y) \text { and } d(y, T x)+\varphi(y)+\varphi(T x)
$$

to $M(x, y, \varphi)$ in (1), that is, we can not replace $M(x, y, \varphi)$ in (1) by

$$
\begin{aligned}
M^{\prime}(x, y, \varphi)= & \max \{d(x, y)+\varphi(x)+\varphi(y), d(x, T x)+\varphi(x)+\varphi(T x), \\
& d(x, T y)+\varphi(x)+\varphi(T y), d(y, T x)+\varphi(y)+\varphi(T x)\} .
\end{aligned}
$$

Example 2.2. Let $X=[0,1]$ with the usual metric $d$ and for each $x \in$ $X$, put

$$
T x=\varphi(x)= \begin{cases}\frac{1}{2}, & \text { if } x \neq \frac{1}{2} ; \\ 0, & \text { if } x=\frac{1}{2} .\end{cases}
$$

Then $(X, d)$ is a complete metric space and $\varphi$ is lower semi-continuous. If $x=y=\frac{1}{2}$, then $d(x, y)+\varphi(x)+\varphi(y)=0$. Therefore, for $0<a<b<+\infty$ with $a \leq d(x, y)+\varphi(x)+\varphi(y) \leq b$, it does not occur $x=y=\frac{1}{2}$. Put $n(a, b)=\inf \{x: a \leq d(x, y)+\varphi(x)+\varphi(y) \leq b\}$ and $\gamma(a, b)=\frac{1}{n(a, b)+1}$.

If $x, y \neq \frac{1}{2}$, then $d(T x, T y)+\varphi(T x)+\varphi(T y)=0$. It implies that

$$
d(T x, T y)+\varphi(T x)+\varphi(T y) \leq \gamma(a, b) M^{\prime}(x, y, \varphi) .
$$

If $x \neq \frac{1}{2}, y=\frac{1}{2}$, then

$$
\begin{aligned}
& d(T x, T y)+\varphi(T x)+\varphi(T y)=d\left(\frac{1}{2}, 0\right)+\varphi\left(\frac{1}{2}\right)+\varphi(0)=1, \\
& d(x, T y)+\varphi(x)+\varphi(T y)=d(x, 0)+\varphi(x)+\varphi(0)=x+1 .
\end{aligned}
$$

This proves that

$$
\begin{aligned}
\gamma(a, b) M^{\prime}(x, y, \varphi) & \geq \gamma(a, b)[d(x, T y)+\varphi(x)+\varphi(T y)] \\
& =\frac{1}{n(a, b)+1}(x+1) \\
& \geq 1 \\
& =d(T x, T y)+\varphi(T x)+\varphi(T y) .
\end{aligned}
$$

If $x=\frac{1}{2}, y \neq \frac{1}{2}$, then

$$
\begin{aligned}
& d(T x, T y)+\varphi(T x)+\varphi(T y)=d\left(0, \frac{1}{2}\right)+\varphi(0)+\varphi\left(\frac{1}{2}\right)=1, \\
& d(y, T x)+\varphi(y)+\varphi(T x)=d(0, y)+\varphi(0)+\varphi(y)=y+1 .
\end{aligned}
$$

This proves that

$$
\begin{aligned}
\gamma(a, b) M^{\prime}(x, y, \varphi) & \geq \gamma(a, b)[d(x, T y)+\varphi(x)+\varphi(T y)] \\
& =\frac{1}{n(a, b)+1}(y+1)
\end{aligned}
$$




$$
\begin{aligned}
& \geq 1 \\
& =d(T x, T y)+\varphi(T x)+\varphi(T y) .
\end{aligned}
$$

By the above, we see that, for all $x, y \in X$ with

$$
a \leq d(x, y)+\varphi(x)+\varphi(y) \leq b
$$

there exists $\gamma(a, b) \in(0,1)$ such that

$$
d(T x, T y)+\varphi(T x)+\varphi(T y) \leq \gamma(a, b) M^{\prime}(x, y, \varphi)
$$

but $T$ has no any fixed point.

Unfortunately, we do not know whether the conclusion of Theorem 2.1 hold if we replace $M(x, y, \varphi)$ in (1) by

$$
N(x, y, \varphi)=\max \{d(x, y)+\varphi(x)+\varphi(y), d(x, T y)+\varphi(x)+\varphi(T y)\}
$$

or by

$$
N(x, y, \varphi)=\max \{d(x, y)+\varphi(x)+\varphi(y), d(y, T x)+\varphi(y)+\varphi(T x)\}
$$

or by

$$
\begin{aligned}
N(x, y, \varphi)= & \max \{d(x, y)+\varphi(x)+\varphi(y), d(x, T x)+\varphi(x)+\varphi(T x), \\
& d(y, T y)+\varphi(y)+\varphi(T y)\} .
\end{aligned}
$$

With some minor changes in the proof of Theorem 2.1, we get the second result which contains $d(y, T y)+\varphi(y)+\varphi(T y)$ in the contraction condition.

Theorem 2.2. Let $(X, d)$ be a complete metric spaces, $\varphi: X \longrightarrow[0, \infty)$ be a lower semi-continuous function and $T: X \longrightarrow X$ be a map. Suppose there exists $k \in(0,1)$ such that for all $x, y \in X$,

$$
\begin{aligned}
& d(T x, T y)+\varphi(T x)+\varphi(T y) \\
\leq & k \max \{d(x, y)+\varphi(x)+\varphi(y), d(x, T x)+\varphi(x)+\varphi(T x), \\
& d(y, T y)+\varphi(y)+\varphi(T y)\} .
\end{aligned}
$$

Then $T$ has a unique fixed point $x^{*} \in X$. Moreover, $\varphi\left(x^{*}\right)=0$.

Proof. Define the sequence $\left\{x_{n}\right\}$ and $\delta_{n}$ as in the proof of Theorem 2.1. From (23), we have

(24) $\delta_{n+1}$

$$
\begin{aligned}
= & d\left(x_{n+1}, x_{n+2}\right)+\varphi\left(x_{n+1}\right)+\varphi\left(x_{n+2}\right) \\
= & d\left(T x_{n}, T x_{n+1}\right)+\varphi\left(T x_{n}\right)+\varphi\left(T x_{n+1}\right) \\
\leq & k \max \left\{d\left(x_{n}, x_{n+1}\right)+\varphi\left(x_{n}\right)+\varphi\left(x_{n+1}\right), d\left(x_{n}, T x_{n}\right)+\varphi\left(x_{n}\right)+\varphi\left(T x_{n}\right),\right. \\
& \left.d\left(x_{n+1}, T x_{n+1}\right)+\varphi\left(x_{n+1}\right)+\varphi\left(T x_{n+1}\right)\right\} \\
\leq & k \max \left\{d\left(x_{n}, x_{n+1}\right)+\varphi\left(x_{n}\right)+\varphi\left(x_{n+1}\right), d\left(x_{n}, x_{n+1}\right)+\varphi\left(x_{n}\right)+\varphi\left(x_{n+1}\right),\right. \\
& \left.d\left(x_{n+1}, x_{n+2}\right)+\varphi\left(x_{n+1}\right)+\varphi\left(x_{n+2}\right)\right\} \\
= & k \max \left\{\delta_{n}, \delta_{n+1}\right\} .
\end{aligned}
$$


Since $k \in(0,1)$, from $(24)$ we get $\delta_{n+1} \leq \delta_{n}$ for all $n \in \mathbb{N}$. Then there exists $r \geq 0$ such that $\lim _{n \rightarrow \infty} \delta_{n}=r$. Taking the limit as $n \rightarrow \infty$ in (24), we get $r \leq k r$. Since $k \in(0,1), r=0$. Therefore,

$$
\lim _{n \rightarrow \infty} \delta_{n}=0 \text {. }
$$

As in the proof of Theorem 2.1, we obtain $\lim _{n \rightarrow \infty} x_{n}=x^{*}$ and $\varphi\left(x^{*}\right)=0$. Also denote $I$ and $J$ as in the proof of Theorem 2.1, we only consider the case $J$ is infinite. From (23), we have

$$
\begin{aligned}
& d\left(x_{n(p)+1}, T x^{*}\right)+\varphi\left(x_{n(p)+1}\right)+\varphi\left(T x^{*}\right) \\
\leq & k \max \left\{d\left(x_{n(p)}, x^{*}\right)+\varphi\left(x_{n(p)}\right)+\varphi\left(x^{*}\right),\right. \\
& d\left(x_{n(p)}, x_{n(p)+1}\right)+\varphi\left(x_{n(p)}\right)+\varphi\left(x_{n(p)+1}\right), \\
& \left.d\left(x^{*}, T x^{*}\right)+\varphi\left(x^{*}\right)+\varphi\left(T x^{*}\right)\right\} .
\end{aligned}
$$

Taking the limit as $p \rightarrow \infty$ in (26), we get

$$
d\left(x^{*}, T x^{*}\right)+\varphi\left(T x^{*}\right) \leq k\left[d\left(x^{*}, T x^{*}\right)+\varphi\left(T x^{*}\right)\right] .
$$

It implies that $d\left(x^{*}, T x^{*}\right)=0$. Therefore, $x^{*}$ is a fixed point of $T$. The rest of the proof is similar to the proof of Theorem 2.1.

From Theorem 2.2, we get [13, Theorem 2.3], [13, Theorem 2.4] as direct consequences.

Corollary 2.2 ([13], Theorem 2.3). Let $(X, d)$ be a complete metric spaces, $\varphi: X \rightarrow[0, \infty)$ be a lower semi-continuous function and $T: X \rightarrow X$ be a given mapping. Suppose that there exists a constant $\gamma \in(0,1 / 2)$ such that for all $x, y \in X$,

$$
\begin{aligned}
& d(T x, T y)+\varphi(T x)+\varphi(T y) \\
\leq \quad & \gamma[d(x, T x)+d(y, T y)+\varphi(x)+\varphi(y)+\varphi(T x)+\varphi(T y)] .
\end{aligned}
$$

Then $T$ has a unique fixed point $z \in X$. Moreover, $\varphi(z)=0$.

Proof. The contraction condition (27) is a special case of (23) with $k=$ $2 \gamma$.

Corollary 2.3 ([13], Theorem 2.4). Let $(X, d)$ be a complete metric spaces, $\varphi: X \rightarrow[0, \infty)$ be a lower semi-continuous function and $T: X \rightarrow X$ be a given mapping. Suppose that there exists a constant $\alpha, \beta, \gamma \in[0, \infty)$, with $\alpha+\beta+\gamma<1$ such that for all $x, y \in X$,

$$
\begin{aligned}
& d(T x, T y)+\varphi(T x)+\varphi(T y) \\
\leq \quad & \alpha[d(x, y)+\varphi(x)+\varphi(y)]+\beta[d(x, T x)+\varphi(x)+\varphi(T x)] \\
& +\gamma[d(y, T y)+\varphi(y)+\varphi(T y)] .
\end{aligned}
$$

Then $T$ has a unique fixed point $z \in X$. Moreover, $\varphi(z)=0$. 
Proof. The contraction condition (28) is a special case of (23) with $k=$ $\alpha+\beta+\gamma$.

The following example shows that Theorem 2.2 is a proper generalization of [13, Theorem 2.3] for a map $T$ on a complete metric space $(X, d)$ with some $\varphi$.

Example 2.3. Let $X=[0,1]$ with the usual metric $d, T x=\frac{x}{3}$ for all $x \in X$ and

$$
\varphi(x)= \begin{cases}0, & \text { if } x \in\left[0, \frac{1}{3}\right] \\ 1, & \text { if } x \in\left(\frac{1}{3}, 1\right]\end{cases}
$$

Then $(X, d)$ is a complete metric space and $\varphi$ is lower semi-continuous. For $x=0$ and $y=\frac{1}{3}$, we have

$$
d(T x, T y)+\varphi(T x)+\varphi(T y)=d\left(0, \frac{1}{9}\right)+\varphi(0)+\varphi\left(\frac{1}{9}\right)=\frac{1}{9}
$$

and

$$
\begin{aligned}
& d(x, T x)+d(y, T y)+\varphi(x)+\varphi(y)+\varphi(T x)+\varphi(T y) \\
= & d(0,0)+d\left(\frac{1}{3}, \frac{1}{9}\right)+\varphi(0)+\varphi\left(\frac{1}{3}\right)+\varphi(0)+\varphi\left(\frac{1}{9}\right) \\
= & \frac{2}{9} .
\end{aligned}
$$

This proves that $(27)$ does not hold for any $\gamma \in\left(0, \frac{1}{2}\right)$. Then Corollary 2.2 is not applicable to $T$ and $\varphi$ on $(X, d)$. However, we have

$$
d(T x, T y)+\varphi(T x)+\varphi(T y)=\frac{|x-y|}{3}
$$

and

$$
\begin{aligned}
& \max \{[d(x, y)+\varphi(x)+\varphi(y)],[d(x, T x)+\varphi(x)+\varphi(T x)], \\
& {[d(y, T y)+\varphi(y)+\varphi(T y)]\} } \\
\geq & d(x, y) \\
= & |x-y| .
\end{aligned}
$$

This proves that (23) holds with $k=\frac{1}{3}$.

Then Theorem 2.2 is applicable to $T$ and $\varphi$ on $(X, d)$.

By using the argument in [13, Section 3], we get following fixed point theorems in partial metric spaces that are generalizations of preceding ones in [13].

Corollary 2.4. Let $(X, p)$ be a complete partial metric spaces, $\varphi: X \longrightarrow$ $[0, \infty)$ be a lower semi-continuous function and $T: X \longrightarrow X$ be a map. Suppose that for any $0<a<b<\infty$, there exists $\gamma(a, b) \in(0,1)$ such that for all $x, y \in X$,

$$
a \leq p(x, y) \leq b \Rightarrow p(T x, T y) \leq \gamma(a, b) \max \{p(x, y), p(x, T x)\}
$$


Then $T$ has a unique fixed point $x^{*} \in X$. Moreover, $p\left(x^{*}, x^{*}\right)=0$.

Proof. By using the notation in Lemma 1.1, we have

$$
p(x, y)=\frac{d_{p}(x, y)+p(x, x)+p(y, y)}{2}
$$

for all $x, y \in X$. Since $(X, p)$ is a complete partial metric space, $\left(X, d_{p}\right)$ is a complete metric space by Lemma 1.2. Put $\varphi(x)=p(x, x)$ for all $x \in X$. Then, by the assumptions, for any $0<a<b<+\infty$, there exists $\gamma(a, b) \in$ $(0,1)$ such that for all $x, y \in X$,

$$
\begin{aligned}
& 2 a \leq d_{p}(x, y)+\varphi(x)+\varphi(y) \leq 2 b \\
\Rightarrow \quad & d_{p}(T x, T y)+\varphi(T x)+\varphi(T y) \\
& \leq \gamma(a, b) \max \left\{d_{p}(x, y)+\varphi(x)+\varphi(y), d_{p}(x, T x)+\varphi(x)+\varphi(T x)\right\} .
\end{aligned}
$$

As in the proof of [13, Corollary 3.1], we see that $\varphi$ is continuous. Then the desired conclusion follows immediately from Theorem 2.1.

Corollary 2.5. Let $(X, p)$ be a complete partial metric spaces, $\varphi: X \longrightarrow$ $[0, \infty)$ be a lower semi-continuous function and $T: X \longrightarrow X$ be a map. Suppose there exists $k \in(0,1)$ such that for all $x, y \in X$,

$$
p(T x, T y) \leq k \max \{p(x, y), p(x, T x), p(y, T y)\} .
$$

Then $T$ has a unique fixed point $x^{*} \in X$. Moreover, $p\left(x^{*}, x^{*}\right)=0$.

Proof. Similar to the proof of Corollary 2.4.

\section{ACKNOWLEDGMENT}

The authors sincerely thank the anonymous referee for valuable comments, especially on comparing obtained results with Tasković's results [14].

\section{REFERENCES}

[1] I. Altun, F. Sola, and H. Simsek, Generalized contractions on partial metric spaces, Topology Appl., Vol. 157 (2010), pp. 2778 - 2785.

[2] V. Berinde, Iterative approximation of fixed points, Lecture Notes in Mathematics, Springer, 2006.

[3] M. Bukatin, R. Kopperman, S. Matthews, and H. Pajoohesh, Partial metric spaces, Amer. Math. Monthly, Vol. 116 (2009), pp. 708 - 718.

[4] P. Collaço and J. C. E. Silva, A complete comparison of 25 contraction conditions, Nonlinear Anal., Vol. 30 (1997), No. 1, pp. 471 - 476.

[5] R. H. Haghi, S. Rezapour, and N. Shahzad, Be careful on partial metric fixed point results, Topology Appl., Vol. 160 (2013), No. 3, pp. 450 - 454.

[6] M. Jleli, E. Karapinar, and B. Samet, Further remarks on fixed-point theorems in the context of partial metric spaces, Abstr. Appl. Anal., Vol. 2013 (2013), pp. 1 - 6.

[7] E. Karapinar and U. Yüksel, Some common fixed point theorems in partial metric spaces, J. Appl. Math., Vol. 2011 (2011), pp. 1 - 16.

[8] S. G. Matthews, Partial metric topology, Papers on general topology and applications, Proc. 8th Summer Conf., Queen's College, 1992. 
[9] S. G. Matthews, Partial metric topology, Ann. New York Acad. Sci., Vol. 728 (1994), pp. $183-197$.

[10] B. E. Rhoades, A comparison of various definition of contractive mappings, Trans. Amer. Math. Soc., Vol. 226 (1977), pp. 257 - 290.

[11] S. Romaguera, A Kirk type characterization of completeness for partial metric spaces, Fixed Point Theory Appl., Vol. 2010 (2010), pp. 1 - 6.

[12] I. A. Rus, Fixed point theory in partial metric spaces, An. Univ. Vest Timiş. Ser. Mat.-Inform., Vol. XLVI (2008), No. 2, pp. 149 - 160.

[13] B. Samet, C. Vetro, and F. Vetro, From metric spaces to partial metric spaces, Fixed Point Theory Appl., Vol. 2013:5 (2013), pp. 1 - 11.

[14] M. R. Tasković, Transversal theory of fixed point fixed apices, and forked points, Math. Morav., Vol. 14 (2010), No. 2, pp. 19 - 97.

Tran VAN AN

Department of Mathematics

VINH UNIVERSITY

VINH CiTY

Nghe An Province

VIET NAM

E-mail address: tvandhv@gmail.com

\section{Le Thanh Quan}

Department of Mathematics

Vinh UNIVERSITY

VINH City

Nghe An Province

VIET NAM

E-mail address: lethanhquan82@gmail.com 